\title{
Assorted Interactions Prevalent in Uracil and Aqueous Gallic Acid Solution Explored by Physicochemical Contrivance
}

\author{
Samapika Ray, Habibur Rahaman, Kanak Roy, Mahendra Nath Roy* \\ Department of Chemistry, University of North Bengal, Darjeeling - 734 013, West Bengal, India.
}

\section{A R T ICLEDETAILS}

\section{Article history:}

Received 08 February 2020

Accepted 28 March 2020

Available online 11 May 2020

\section{Keywords:}

Solute-Cosolute Interactions

Apparent Molar Volume

Viscosity B-Coefficient

\begin{abstract}
A B S T R A C T
The solute-cosolute interaction of uracil by gallic acid has been studied through physicochemical investigation in aqueous environment. Here, we have carried out the density $(\rho)$ and viscosity $(\eta)$ measurements of uracil in $w_{1}=0.001,0.002$ and 0.003 mass fraction of aqueous gallic acid binary mixtures at $T=298.15 \mathrm{~K}, 303.15 \mathrm{~K}$ and $308.15 \mathrm{~K}$ at pressure 1.013 bar. Some important parameters have been derived from the above physicochemical method, namely, limiting apparent molar volume $\left(\varphi_{\nu}{ }^{0}\right)$ and viscosity $B$-coefficients using extended Masson equation and Jones-Dole equation respectively. The refractive index $\left(n_{D}\right)$ has been done on the same system at $T=298.15 \mathrm{~K}$. Lorentz-Lorenz equation has used to evaluate molar refractive index $\left(R_{M}\right)$ and limiting molar index $\left(R_{M^{0}}\right)$. The NMR study used to measure the plausible selective site of solute-cosolute interaction.
\end{abstract}

\section{Introduction}

Gallic acid is a secondary polyphenolic functionality metabolite natural antioxidant. It is a water-soluble organic compound present in grapes and in the leaves of many plants. Gallic acid esters are used to in vitro potent antioxidant, such as tannins, catechin gallates and aliphatic gallates. However, gallic acid itself also acts as in vitro anticarcinogenic and antiangiogenic activity. Apart from its phytochemical role, gallic acid is also used in ink dyes, and the manufacture of paper, pharmaceutical industry, starting material for the synthesis of psychedelic alkaloid mescaline [1-5].

Uracil is a common naturally occurring pyrimidine group only found in RNA, its base pairs with adenine and is replaced by thymine in DNA. Uracil is planar and unsaturated with the molecular formula $\mathrm{C}_{4} \mathrm{H}_{4} \mathrm{~N}_{2} \mathrm{O}_{2}$ and has the ability to absorb light. Uracil can bind with base pairs depending on arrangement, in RNA it binds to adenine via two hydrogen bonds. Uracil is use in the body is to help carry out the synthesis of many enzymes necessary for cell function through bonding with ribose and phosphates [6-8].

To the best of our knowledge, the studies in the present ternary solution systems have not been reported earlier. Therefore, in present study we have endeavored to make certain nature of interaction of solute itself (uracil) and with co-solute (gallic acid) in $w_{1}=0.001,0.002$ and 0.003 mass fraction of aqueous medium at different temperatures $298.15 \mathrm{~K}-308.15 \mathrm{~K}$ with 5 interval to explain various noncovalent interactions prevailing in the ternary systems under investigation.

\section{Experimental Methods}

\subsection{Materials}

Uracil and Gallic acid were purchased from Sigma-Aldrich. The mass fractions purity of both was $\geq 0.99$. The reagents were always placed in the desiccators over $\mathrm{P}_{2} \mathrm{O}_{5}$ to keep them in dry atmosphere. These chemicals were used as received without further purification. The provenance and purity of the chemical used has been depicted in Table 1.

\subsection{Procedure}

Solubility of the uracil and gallic acid in water (deionised, doubly distilled water) and in uracil and gallic acid solutions have been checked

\section{*Corresponding Author:mahendraroy2002@yahoo.co.in(Mahendra Nath Roy)}

precisely, prior to the experimental work and observe that uracil is soluble in all proportion of aqueous gallic acid solution. The mother solutions of uracil were prepared by mass (Mettler Toledo AG-285 with uncertainty $0.0003 \mathrm{~g}$ ) and then the working solutions (six sets) were prepared by mass dilution. The conversion of molarity into molality [9] has been done using experimental density values of respective solutions.

Table 1 Source and purity of the chemicals

\begin{tabular}{llll}
\hline Chemical name & Source & $\begin{array}{l}\text { Mass fraction } \\
\text { purity }\end{array}$ & $\begin{array}{l}\text { Purification } \\
\text { method }\end{array}$ \\
\hline Uracil & SD Fine-Chem Ltd. & $\geq 0.99$ & Used as procured \\
Gallic acid & SD Fine-Chem Ltd. & $\geq 0.99$ & Used as procured \\
\hline
\end{tabular}

The densities $(\rho)$ of the solutions were measured by means of vibrating u-tube Anton Paar digital density meter (DMA 4500M) with a precision of

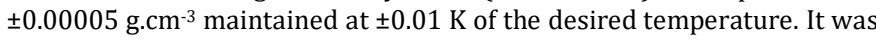
calibrated by passing deionised, triply distilled water and dry air [10].

The viscosities $(\eta)$ were measured using a Brookfield DV-III Ultra Programmable Rheometer with fitted spindle size-42. The detail description has already been described in the previous work [11].

Refractive index $\left(n_{D}\right)$ was measured with the help of a Digital Refractometer Mettler Toledo. The light source was LED, $\lambda=589.3 \mathrm{~nm}$. The refractometer was calibrated twice using distilled water and calibration was checked after every few measurements [12]. The uncertainty of refractive index measurement was \pm 0.0002 units.

${ }^{1} \mathrm{H}-\mathrm{NMR}$ spectra were recorded at $400 \mathrm{MHz}$ Bruker instrument using $\mathrm{D}_{2} \mathrm{O}$ as reference solvent at $298.15 \mathrm{~K}$.

\section{Results and Discussion}

The physical parameters of binary mixtures in different mass fractions $\left(w_{1}=0.001,0.002,0.003\right)$ of aqueous gallic acid (GA) solutions at three different temperatures $(298.15 \mathrm{~K}, 303.15 \mathrm{~K}, 308.15 \mathrm{~K})$ and at $1.013 \mathrm{bar}$ have been reported in Table 2. The experimental measured values of density, viscosity of uracil (UA) as a function of concentration (molality), in different mass fractions of aqueous gallic acid (GA) mixture at three above mentioned temperatures have been listed in Table 3.

\subsection{Apparent Molar Volume}

Volumetric properties, like, apparent molar volume $\left(\varphi_{V}\right)$ and limiting apparent molar volume $\left(\varphi_{V}{ }^{0}\right)$ consider important tools for understanding of interactions taking place in solution systems. The apparent molar volume can be regarded to be the sum of the geometric volume of the 
central solute molecule and changes in the solvent volume due to its interaction with the solute around the peripheral or co-sphere. Therefore, the apparent molar volumes $\left(\varphi_{V}\right)$ have been determined from the solutions densities using the suitable equation and the values are given in Table 4.

$$
\varphi_{V}=M / \rho-1000\left(\rho-\rho_{0}\right) / m \rho \rho_{0}
$$

where $M$ is the molar mass of the solute, $m$ is the molality of the solution, $\rho$ and $\rho_{0}$ are the density of the solution and aqueous gallic acid mixture respectively.

Table 2 Experimental values of density $(\rho)$, viscosity $(\eta)$ and refractive index $\left(n_{D}\right)$ at $298.15 \mathrm{~K}$ and at pressure 1.013 bar of different mass fraction $\left(w_{1}\right)$ of aq. gallic acid mixtures*

\begin{tabular}{lllll}
\hline $\begin{array}{l}\text { Aq. Gallic acid } \\
\text { Mixture }\left(\mathrm{w}_{1}\right)\end{array}$ & Temp., & $\begin{array}{l}\rho \times 10^{-3} \\
\mathrm{~kg} \cdot \mathrm{m}^{-3}\end{array}$ & $\begin{array}{l}\eta \\
\mathrm{mP} \cdot \mathrm{s}\end{array}$ & $n_{D}$ \\
\hline 0.001 & 298.15 & 0.99689 & 0.91 & 1.3319 \\
& 303.15 & 0.99547 & 0.83 & \\
0.002 & 308.15 & 0.99395 & 0.74 & \\
& 298.15 & 0.99698 & 0.91 & 1.3324 \\
0.003 & 303.15 & 0.99556 & 0.84 & \\
& 308.15 & 0.99396 & 0.76 & \\
& 298.15 & 0.99702 & 0.92 & 1.3329 \\
& 303.15 & 0.99564 & 0.85 & \\
\hline
\end{tabular}

*Standard uncertainties $u$ are: $u(\rho)=0.002 \mathrm{~kg} \cdot \mathrm{m}^{-3}, u(\eta)=0.02 \mathrm{mP} \cdot \mathrm{s}, u\left(n_{D}\right)=0.0002$ and $u(T)=0.01 K,(0.68$ level of confidence $)$

Table 3 Experimental values of density $(\rho)$ and viscosity $(\eta)$, Uracil in different mass fractions of aqueous Gallic acid mixture $\left(w_{1}\right)$ at three different temperatures and at pressure $1.013 \mathrm{bar}^{*}$

\begin{tabular}{|c|c|c|c|c|c|c|c|c|}
\hline $\begin{array}{l}\text { am } \\
\text { molkg-1 }^{-1}\end{array}$ & $\begin{array}{l}\rho \times 10^{-3} \\
\mathrm{kgm}^{-3}\end{array}$ & $\begin{array}{l}\eta \\
\text { mP.s }\end{array}$ & $\begin{array}{l}\text { am } \\
\text { molkg-1 }\end{array}$ & $\begin{array}{l}\rho \times 10^{-3} \\
\mathrm{kgm}^{-3}\end{array}$ & $\begin{array}{l}\eta \\
\text { mP.s }\end{array}$ & $\begin{array}{l}\text { am } \\
\text { molkg-1 }^{-1}\end{array}$ & $\begin{array}{l}\rho \times 10^{-3} \\
\mathrm{kgm}^{-3}\end{array}$ & $\begin{array}{l}\eta \\
\text { mP.s }\end{array}$ \\
\hline & $\mathrm{w}_{1}=0.001$ & & & $\mathrm{w}_{1}=0.002$ & & & $\mathrm{w}_{1}=0.003$ & \\
\hline Temp. & $298.15 \mathrm{~K}$ & & & $298.15 \mathrm{~K}$ & & & $298.15 \mathrm{~K}$ & \\
\hline 0.0100 & 0.99722 & 0.92 & 0.0100 & 0.99726 & 0.93 & 0.0100 & 0.99731 & 0.93 \\
\hline 0.0252 & 0.99790 & 0.93 & 0.0252 & 0.99795 & 0.94 & 0.0252 & 0.99799 & 0.94 \\
\hline 0.0404 & 0.99897 & 0.94 & 0.0404 & 0.99897 & 0.95 & 0.0404 & 0.99896 & 0.96 \\
\hline 0.0556 & 1.00022 & 0.94 & 0.0556 & 1.00027 & 0.96 & 0.0556 & 1.00018 & 0.97 \\
\hline 0.0709 & 1.00150 & 0.95 & 0.0709 & 1.00159 & 0.97 & 0.0709 & 1.00157 & 0.98 \\
\hline 0.0863 & 1.00304 & 0.96 & 0.0863 & 1.00317 & 0.98 & 0.0863 & 1.00316 & 0.99 \\
\hline Temp. & $298.15 \mathrm{~K}$ & & & $298.15 \mathrm{~K}$ & & & $298.15 \mathrm{~K}$ & \\
\hline 0.0101 & 0.99518 & 0.84 & 0.0101 & 0.99588 & 0.85 & 0.0101 & 0.99593 & 0.86 \\
\hline 0.0252 & 0.99652 & 0.85 & 0.0252 & 0.99651 & 0.86 & 0.0252 & 0.99655 & 0.87 \\
\hline 0.0404 & 0.99759 & 0.86 & 0.0404 & 0.99756 & 0.87 & 0.0404 & 0.99755 & 0.88 \\
\hline 0.0557 & 0.99834 & 0.87 & 0.0557 & 0.99877 & 0.88 & 0.0557 & 0.99874 & 0.89 \\
\hline 0.0710 & 1.00014 & 0.87 & 0.0710 & 1.00025 & 0.89 & 0.0710 & 1.00014 & 0.90 \\
\hline 0.0864 & 1.00158 & 0.88 & 0.0864 & 1.00174 & 0.89 & 0.0864 & 1.00173 & 0.91 \\
\hline Temp. & $298.15 \mathrm{~K}$ & & & $298.15 \mathrm{~K}$ & & & $298.15 \mathrm{~K}$ & \\
\hline 0.0101 & 0.99425 & 0.75 & 0.0101 & 0.99429 & 0.77 & 0.0101 & 0.99432 & 0.78 \\
\hline 0.0253 & 0.99491 & 0.75 & 0.0253 & 0.99491 & 0.77 & 0.0253 & 0.99487 & 0.79 \\
\hline 0.0405 & 0.99588 & 0.76 & 0.0405 & 0.99593 & 0.78 & 0.0405 & 0.99583 & 0.80 \\
\hline 0.0558 & 0.99716 & 0.77 & 0.0558 & 0.99713 & 0.79 & 0.0558 & 0.99699 & 0.80 \\
\hline 0.0712 & 0.99846 & 0.77 & 0.0712 & 0.99852 & 0.80 & 0.0712 & 0.99845 & 0.81 \\
\hline 0.0866 & 0.99998 & 0.78 & 0.0866 & 0.99991 & 0.81 & 0.0866 & 0.99989 & 0.82 \\
\hline
\end{tabular}

amolality has been expressed per $\mathrm{kg}$ (gallic acid + water) solvent mixture

Table 4 Apparent molar volume $\left(\varphi_{V}\right)$ and $\left(\eta_{r}-1\right) / \sqrt{m}$ of uracil in different mass fraction $\left(w_{1}\right)$ of aqueous gallic acid mixtures at three different temperatures*

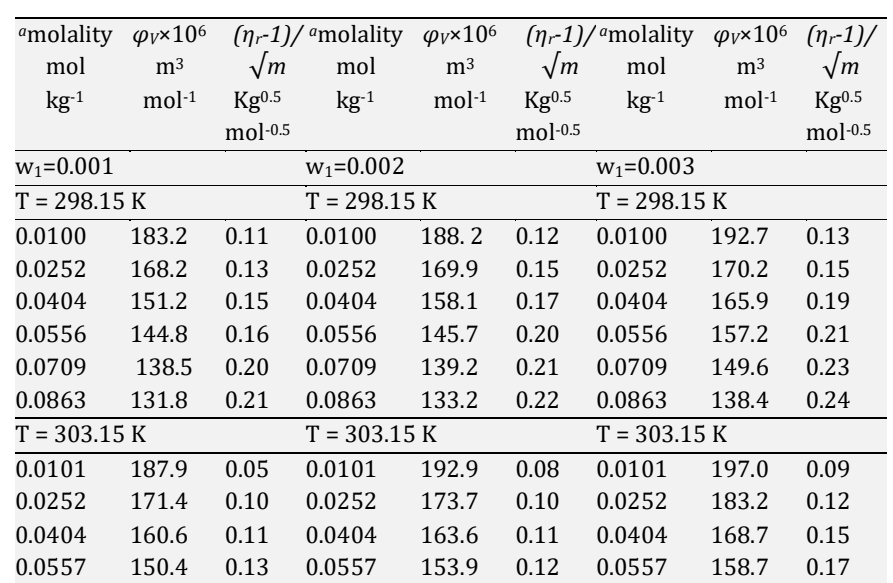

\begin{tabular}{lllllllll}
\hline 0.0710 & 140.1 & 0.14 & 0.0710 & 143.5 & 0.15 & 0.0710 & 148.1 & 0.21 \\
0.0864 & 135.5 & 0.15 & 0.0864 & 138.6 & 0.20 & 0.0864 & 142.1 & 0.22 \\
\hline \multicolumn{7}{l}{$\mathrm{T}=308.15 \mathrm{~K}$} \\
\hline 0.0101 & 194.2 & 0.07 & 0.0101 & 196.2 & 0.06 & 0.0101 & 200.4 & 0.08 \\
0.0253 & 175.1 & 0.10 & 0.0253 & 181.2 & 0.10 & 0.0253 & 183.1 & 0.11 \\
0.0405 & 162.4 & 0.13 & 0.0405 & 167.9 & 0.13 & 0.0405 & 171.4 & 0.16 \\
0.0558 & 150.3 & 0.15 & 0.0558 & 157.3 & 0.16 & 0.0558 & 160.4 & 0.18 \\
0.0712 & 142.5 & 0.17 & 0.0712 & 148.9 & 0.18 & 0.0712 & 150.7 & 0.21 \\
0.0866 & 138.9 & 0.18 & 0.0866 & 141.8 & 0.20 & 0.0866 & 143.1 & 0.22 \\
\hline
\end{tabular}

*Standard uncertainties $u$ are: $u(T)=0.01 \mathrm{~K}$, the accuracy of $\varphi_{V}$ is $1.86 \times 10^{-6} \mathrm{~m}^{3} \mathrm{~mol}^{-1}$ and $\left(\eta_{r}-1\right) / \sqrt{m}$ is $0.004 \mathrm{~kg}^{1 / 2} \mathrm{~mol}^{-1 / 2}$ (0.68 level of confidence)

a molality has been expressed per $\mathrm{kg}$ of (gallic acid + water) solvent mixture

The values of $\left(\varphi_{V}\right)$ are positive and large for all the systems, signifying strong solute-cosolute interactions. The apparent molar volumes $\left(\varphi_{V}\right)$ are found to decrease with increasing concentration (molality, $m$ ) of uracil in same mass fraction of aqueous gallic acid at same temperature. It is also found that apparent molar volumes $\left(\varphi_{V}\right)$ increase with both increasing temperature as well as mass fraction of aqueous gallic acid solution and varied with $\sqrt{m}$ and could be least-squares fitted to the extended Masson equation [13] from where limiting molar volume, $\varphi_{V}{ }^{0}$ (infinite dilution partial molar volume) have been estimated and the values have been represented in Table 5 .

$$
\varphi_{\mathrm{V}}=\varphi_{\mathrm{V}}{ }^{0}+\mathrm{S}_{\mathrm{V}}{ }^{*} \sqrt{\mathrm{m}}
$$

where $\varphi_{V}{ }^{0}$ is the apparent molar volume at infinite dilution, $S_{V}{ }^{*}$ is the experimental slope. At infinite dilution solute molecule is surrounded only by the solvent molecules and remains infinite distant from each other. As a consequence, that $\varphi_{V}{ }^{0}$ is unaltered by itself interaction of uracil molecules and it is a measure only of the solute-cosolute (uracil-gallic acid) interaction.

Table 5 Limiting apparent molar volume $\left(\varphi_{V}{ }^{0}\right)$, experimental slope $\left(S_{V}{ }^{*}\right)$, viscosity $A$ and $B$-coefficient of uracil in different mass fraction $\left(w_{1}\right)$ of aqueous gallicic acid

\begin{tabular}{|c|c|c|c|c|c|}
\hline \multicolumn{2}{|c|}{ Mass fraction $\mathrm{T}$} & \multirow{2}{*}{$\begin{array}{l}\varphi_{V^{0}} \times 10^{6} \\
\mathrm{~m}^{3} \mathrm{~mol}^{-1}\end{array}$} & \multirow{2}{*}{$\begin{array}{l}S_{\mathrm{V}^{*} \times 10^{6}} \\
\mathrm{~m}^{3} \mathrm{~mol}^{-3 / 2} \mathrm{~kg}^{1 / 2}\end{array}$} & \multirow{2}{*}{$\begin{array}{l}B \\
\mathrm{~kg} \mathrm{~mol}^{-1}\end{array}$} & \multirow{2}{*}{$\begin{array}{l}A \\
\mathrm{~kg}^{1 / 2} \mathrm{~mol}^{-1 / 2}\end{array}$} \\
\hline$\left(w_{1}\right)$ & $\mathrm{K}$ & & & & \\
\hline \multirow{3}{*}{0.001} & 298.15 & 220.18 & -417.12 & 0.41 & 0.02 \\
\hline & 303.15 & 225.45 & -451.27 & 0.49 & 0.01 \\
\hline & 308.15 & 231.28 & -493.79 & 0.67 & 0.05 \\
\hline \multirow{3}{*}{0.002} & 298.15 & 225.98 & -499.65 & 0.53 & 0.04 \\
\hline & 303.15 & 230.63 & -477.45 & 0.66 & 0.02 \\
\hline & 308.15 & 236.16 & -463.92 & 0.78 & 0.01 \\
\hline \multirow{3}{*}{0.003} & 298.15 & 230.72 & -448.89 & 0.65 & 0.03 \\
\hline & 303.15 & 235.51 & -453.56 & 0.77 & 0.01 \\
\hline & 308.15 & 241.12 & -442.87 & 0.93 & 0.04 \\
\hline
\end{tabular}
mixtures at three different temperatures*

*Standard uncertainties values of $u$ are: $u(T)=0.01 \mathrm{~K}$

An inspection of Table 5 shows that $\varphi_{\nu}{ }^{0}$ are large and positive for all uracil at all the studied temperatures, suggesting the presence of strong solute-cosolute interaction. Comparing $\varphi_{V}{ }^{0}$ with $S_{V}{ }^{*}$ values show that the magnitude of $\varphi_{V}{ }^{0}$ is greater than $S_{V}{ }^{*}$, suggesting that solute-cosolute interactions predominates over itself interaction of solute molecules in all solutions at all studied temperatures. Moreover, $S_{V}{ }^{*}$ values are negative at all studied temperatures indicates force of itself interaction of uracil molecules is very poor.

The variation of $\varphi_{V}{ }^{0}$ with temperature are fitted to the following polynomial,

$$
\varphi_{V}^{0}=a_{0}+a_{1} T+a_{2} T^{2}
$$

where $T$ is the temperature in $\mathrm{K}$ and $a_{0}, a_{1}$ and $a_{2}$ are the empirical coefficients depending on the solute, mass fraction of cosolute gallic acid. Values of coefficients of the above equation for the in aqueous gallic acid mixtures are reported in Table 6 .

Table 6 Values of various coefficients and standard deviation of equation-3 for uracil acid in different aqueous gallic acid solutions*

\begin{tabular}{lllll}
\hline $\begin{array}{l}\text { Aq. Gallic acid } \\
\text { Mixture }\left(w_{1}\right)\end{array}$ & $\begin{array}{l}a_{0} \times 10^{6} \\
\mathrm{~m}^{3} \mathrm{~mol}^{-1}\end{array}$ & $\begin{array}{l}a_{1} \times 10^{6} \\
\mathrm{~m}^{3} \mathrm{~mol}^{-1} \mathrm{~K}^{-1}\end{array}$ & $\begin{array}{l}a_{2} \times 10^{6} \\
\mathrm{~m}^{3} \mathrm{~mol}^{-1} \mathrm{~K}^{-2}\end{array}$ & $\begin{array}{l}\left(\delta \varphi_{\mathrm{E}}^{0} / \delta \mathrm{T}\right) \mathrm{p} \times 10^{6} \\
\mathrm{~m}^{3} \mathrm{~mol}^{-1} \mathrm{~K}^{-2}\end{array}$ \\
\hline 0.001 & 2014.72 & -15.21 & 0.01 & 0.03 \\
0.002 & 2141.61 & -14.24 & 0.02 & 0.06 \\
0.003 & 2212.43 & -13.28 & 0.02 & 0.05 \\
Average SD & 3.1 & 0.011 & 0.0002 & 0.0001 \\
\hline
\end{tabular}

The limiting apparent molar expansibilities, $\varphi_{E}{ }^{0}$, can be evaluated by the following equation,

$$
\varphi_{\mathrm{E}}^{0}=\left(\delta \varphi_{\mathrm{V}}{ }^{0} / \delta \mathrm{T}\right)_{\mathrm{P}}=\mathrm{a}_{1}+2 \mathrm{a}_{2} \mathrm{~T}
$$


The limiting apparent molar expansibilities, $\varphi_{E}{ }^{0}$, change in magnitude with the change of temperature. The values of $\varphi_{E}{ }^{0}$ for different solutions of studied gallic acid at $T=298.15,303.15$ and $308.15 \mathrm{~K}$ are shown in Table 7 .

Table 7 Limiting apparent molar expansibilities $\left(\varphi_{E}{ }^{0}\right)$ for uracil in different mass fraction of aqueous gallic acid $\left(w_{1}\right)$ at different temperature

\begin{tabular}{llll}
\hline Aq. gallic acid mixture $\left(w_{1}\right)$ & \multicolumn{4}{l}{$\varphi_{E}^{0} \times 10^{6}, \mathrm{~m}^{3} \mathrm{~mol}^{-1} \mathrm{~K}^{-1}$} \\
\hline $\mathrm{T} / \mathrm{K}$ & 298.15 & 303.15 & 308.15 \\
0.001 & 1.012 & 1.142 & 1.253 \\
0.002 & 3.729 & 3.928 & 4.227 \\
0.003 & -1.533 & -1.344 & -1.133 \\
Average SD & 0.003 & 0.003 & 0.002 \\
\hline
\end{tabular}

All the values of $\varphi_{E}^{0}$ shown in the Table 7 are positive for uracil in aqueous gallic acid and studied temperature. This fact helps to explain the absence of caging or packing effect for the gallic acid in solution [14].

The long-range structure-making and breaking capacity of the solute in mixed system can be determined by examining the sign of $\left(\delta \varphi_{E}{ }^{0} / \delta T\right)_{P}$ developed by Hepler [15].

$$
\left(\delta \varphi_{E}{ }^{0} / \delta T\right)_{P}=\left(\delta^{2} \varphi_{V}{ }^{0} / \delta T^{2}\right)_{P}=2 a_{2}
$$

The positive sign or small negative of $\left(\delta \varphi_{E}{ }^{0} / \delta T\right)_{P}$ signifies the molecule is a structure-maker; otherwise, it is a structure-breaker [16]. The perusal of Table 6 shows that, $\left(\delta \varphi_{E}{ }^{0} / \delta T\right)_{P}$ values of citric acid are all positive under investigation. It shows the more symmetric rearrangement of the interacting molecules (uracil and gallic acid) with the formation of $\mathrm{H}$ bonding, Van der Waals forces, dipole-dipole interactions etc. This symmetric arrangement is signifying the molecules of uracil and gallic acid is definitely interacting with structure-making tendency in all of the studied solution systems. The Table 6 also showing the positively magnitude of $\left(\delta \varphi_{E}{ }^{0} / \delta T\right)_{P}$ values in of uracil is depicting this structuremaking tendency.

\subsection{Viscosity}

The experimental viscosity data for studied systems are listed in Table 3. The relative viscosity $\left(\eta_{r}\right)$ has been calculated using extended Jones-Dole equation [17] for non-electrolytes.

$$
\left(\eta / \eta_{0}-1\right) / \sqrt{m}=\left(\eta_{r}-1\right) / \sqrt{m}=A+B \cdot \sqrt{m}
$$

where $\eta_{r}=\eta / \eta_{0}$ is the relative viscosity, $\eta$ and $\eta_{0}$ are the viscosities of ternary solutions (uracil+gallic acid) and solvent (aqueous mixture of gallic acid) respectively and $m$ is the molality of uracil in ternary solutions. Where $A$ is known as Falkenhagen coefficient [18] as it is determined by the ionic attraction theory of Falkenhagen-Vernon and $B$ is empirical constants known as viscosity $B$ - coefficients, which are specifying to the interaction of solute itself and/or with cosolute molecules respectively. The values of $A$ - and $B$-coefficients are estimated by least-square polynomial method by plotting $\left(\eta_{r}-1\right) / \sqrt{m}$ against $\sqrt{m}$ with second order and reported in Table 4.

It is observed from Table 4 the values of the $A$-coefficient are found to decrease with increase in temperature. This fact indicates the presence of very weak solute-solute interaction and also in excellent agreement with those obtained from $S_{V}{ }^{*}$ values.

The valuable information about the solvation of the solvated solutes and their effects on the structure of the cosolute gallic acid in the local vicinity of the solute (uracil) molecules in solutions has been obtained from viscosity $B$-coefficient [19]. It is found from Table 4 ; the values of $B$ coefficient are positive and much higher than $A$-coefficient which signifies solute-cosolute interaction is dominant over solute-solute and cosolutecosolute interaction. It is also observed that the positive magnitude of viscosity $B$-coefficient increases with increasing temperature and also increases with an increase in mass fraction of aqueous gallic acid mixture which suggests that solute-cosolute interaction is strengthened with rise in temperature as well as mass fraction of aqueous uric acid mixture. These results are in good agreement with those obtained from limiting apparent molar volume $\varphi_{\nu}{ }^{0}$ values.

It is observed from Table 4 that the values of the $B$-coefficient of citric acid increases with temperature, i.e., the $d B / d T$ values are positive. From Table 8 , the small positive $d B / d T$ values for the citric acid behaves behave almost as structure-maker.

Furthermore, it is attractive to observe that there is linear correlation between viscosity $B$-coefficients of the studied citric acid with the limiting apparent molar volumes $\left(\varphi_{\nu}{ }^{0}\right)$ in different mass fraction of aqueous uric acid solutions. From the above fact it means
The coefficients $A_{1}$ and $A_{2}$ are listed in Table 8 . As both viscosities $B$ coefficient and limiting apparent molar volumes define the solute-solvent interaction in solution. The linear variation of viscosity $B$-coefficient and limiting apparent molar volume $\left(\varphi_{V}{ }^{0}\right)$ reflects the positive slope (or $A_{2}$ ).

Table 8 Values of $d B / d T, A_{1}, A_{2}$ coefficients for the uracil in different mass fraction of aqueous gallic acid $\left(w_{1}\right)$ at studied temperatures ${ }^{*}$

\begin{tabular}{llll}
\hline Aq. Gallic acid Mixture $\left(w_{1}\right)$ & $d B / d T$ & $A_{1}$ & $A_{2}$ \\
\hline 0.001 & 0.031 & -6.746 & 0.021 \\
0.002 & 0.026 & -7.766 & 0.022 \\
0.003 & 0.035 & -8.295 & 0.034 \\
$\begin{array}{l}\text { Average standard } \\
\text { deviation }\end{array}$ & 0.001 & 0.005 & 0.003 \\
\hline
\end{tabular}

* Standard uncertainties values of $u$ are: $u(T)=0.01 \mathrm{~K}$

It is evident from this study, that there is a strong interaction between uracil and gallic acid and it becomes stronger with rise in temperature. As molecules of uracil are engaged with the gallic acid molecules, the interaction among the gallic acid molecules becomes less effective. We have obtained the derived parameters like, limiting apparent molar volume $\left(\varphi_{V}{ }^{0}\right)$, viscosity $B$-coefficient by interpolation and presented in Table 5. The positive and significant magnitude of $\varphi_{V}{ }^{0}$ and $B$-coefficient from Table 5 clearly indicates that the limiting apparent molar volume $\left(\varphi_{V}{ }^{0}\right)$, viscosity $B$-coefficient is increases with increasing mass fraction of uracil, which indicates the positive effect of interaction of uracil with gallic acid.

\subsection{Refractive Index}

The measurement of refractive index is also a suitable method for investigating the molecular interaction existing in solution. The molar refraction $\left(R_{M}\right)$ can be evaluated from the Lorentz-Lorenz relation [20]. The refractive index of a substance is defined as the ratio $c_{o} / c$, where $c$ and $c_{o}$ is the velocity of light in the medium and in vacuum respectively. Stated more simply that the refractive index of a compound describes its ability to refract light as it passes from one medium to another and thus, the higher the refractive index of a compound, the more the light is refracted [21].

As stated by Deetlefs et al. [22] the refractive index of a substance is higher when its molecules are more tightly packed or in general when the compound is denser. Hence, a perusal of Table 9 it has found as the refractive index and the molar refraction are higher for the studied uracil and in all the mass fraction of aqueous gallic acid, indicating to the fact that the molecules are more tightly packed in the solution.

Table 9 Refractive index $\left(n_{D}\right)$, molar refraction $\left(R_{M}\right)$ and limiting molar refraction $\left(R_{M}{ }^{0}\right)$ uracil in different mass fraction of aqueous gallic acid solutions at $298.15 \mathrm{~K}$ and

\begin{tabular}{|c|c|c|c|}
\hline $\begin{array}{l}\text { molality } \\
\mathrm{mol} \cdot \mathrm{kg}^{-1}\end{array}$ & $n_{D}$ & $\begin{array}{l}R_{M \times 10^{6}} \\
\mathrm{~m}^{3} \mathrm{~mol}^{-1}\end{array}$ & $\begin{array}{l}R_{M^{0} \times 10^{6}} \\
\mathrm{~m}^{3} \mathrm{~mol}^{-1}\end{array}$ \\
\hline \multicolumn{4}{|l|}{$w_{1}=0.001$} \\
\hline 0.0100 & 1.3320 & 44.23 & \multirow{6}{*}{$44.24 \pm 0.03$} \\
\hline 0.0252 & 1.3323 & 44.23 & \\
\hline 0.0404 & 1.3328 & 44.23 & \\
\hline 0.0556 & 1.3333 & 44.25 & \\
\hline 0.0709 & 1.3338 & 44.25 & \\
\hline 0.0863 & 1.3345 & 44.26 & \\
\hline \multicolumn{4}{|l|}{$w_{1}=0.002$} \\
\hline 0.0100 & 1.3325 & 44.27 & \multirow{6}{*}{$44.28 \pm 0.03$} \\
\hline 0.0252 & 1.3327 & 44.27 & \\
\hline 0.0404 & 1.3333 & 44.28 & \\
\hline 0.0556 & 1.3338 & 44.28 & \\
\hline 0.0709 & 1.3343 & 44.31 & \\
\hline 0.0863 & 1.3349 & 44.31 & \\
\hline \multicolumn{4}{|l|}{$w_{1}=0.003$} \\
\hline 0.0100 & 1.3333 & 44.36 & \multirow{6}{*}{$43.42 \pm 0.02$} \\
\hline 0.0252 & 1.3336 & 44.37 & \\
\hline 0.0404 & 1.3343 & 44.42 & \\
\hline 0.0556 & 1.3350 & 44.43 & \\
\hline 0.0709 & 1.3356 & 44.45 & \\
\hline 0.0863 & 1.3363 & 44.46 & \\
\hline
\end{tabular}
at pressure 1.013 bar $^{*}$

amolality has been expressed per kilogram of (gallic acid + water) solvent mixture

The limiting molar refraction $\left(R_{M^{0}}\right)$ estimated from the following Eq. (14) and presented in Table 9.

$$
R_{M}=R_{M}{ }^{0}+R_{S} \sqrt{\mathrm{m}}
$$


Accordingly, it has been found that the higher values of refractive index and $R_{M}{ }^{0}$ which representing the fact that the molecules of uracil and are more tightly packed and greater solute-solvent interaction with gallic acid molecules than solute solvent interaction. This is also in good agreement with the results obtained from apparent molar volume and viscosity $B$ coefficients discussed above.

\subsection{NMR Study}

The site selective solute and cosolute interaction have been observed in ${ }^{1} \mathrm{H}$ NMR study. Gallic acid (GA) shows NMR peak at $\delta: 6.67$ for phenolic $\mathrm{OH}$ group. Uracil (UA) shows NMR peak at $\delta: 7.44$ and $\delta: 5.71$ for C(5) and C(6) protons. NMR spectra suggest that interaction occurs through $\mathrm{C}(5)$ and $\mathrm{C}(6)$ protons of uracil with phenolic $\mathrm{OH}$ group of gallic acid. This is shown in Fig. 1and Scheme 1. Due to this weak interaction the C(5) and C(6) proton signal in uracil and gallic acid mixture (GU) shifts towards upfield and recorded at $\delta: 7.24$ and $\delta: 5.57$. This is obvious for the specific solute and cosolute interaction. This supports all the above physicochemical experiments along with spectroscopic data [23].

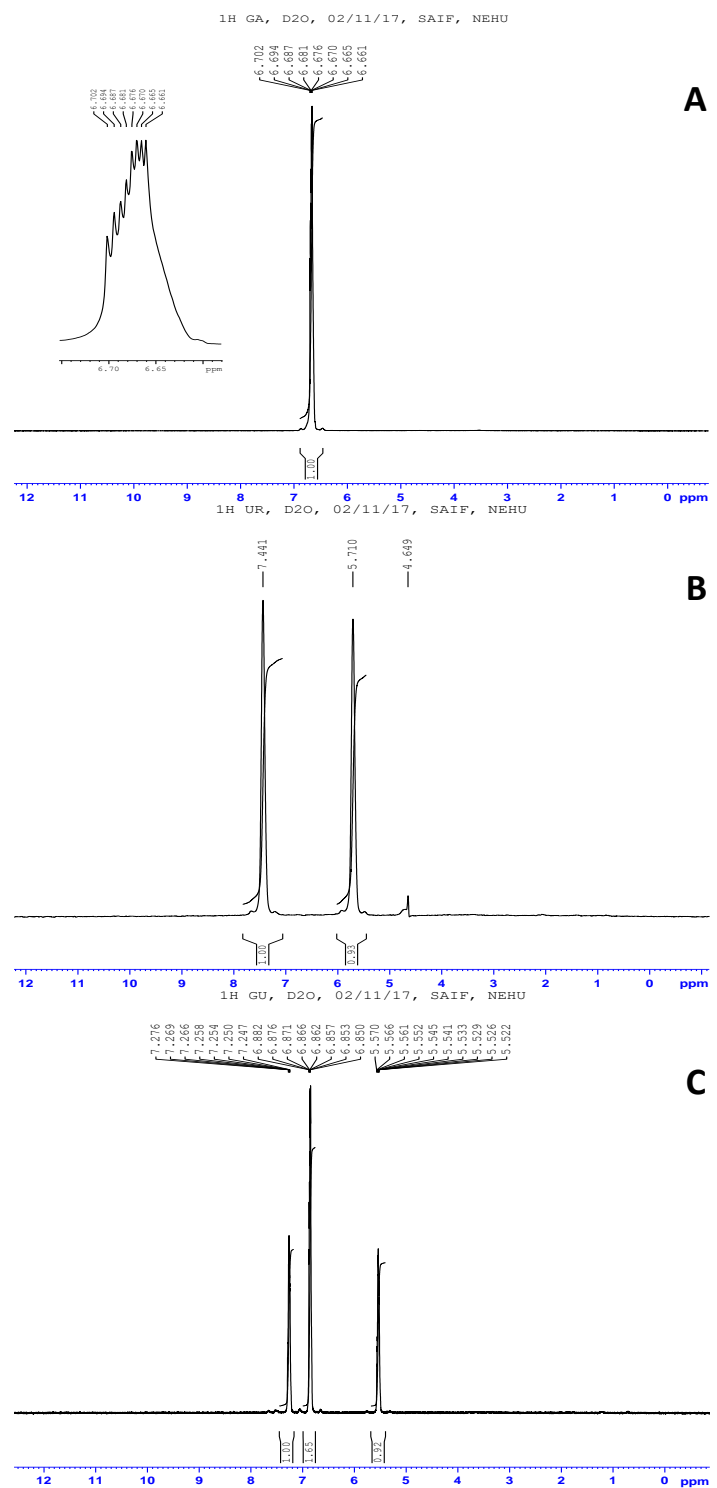

Fig. 1 Plot of ${ }^{1}$ HNMR spectra of a) gallic acid (GA), b) uracil (UA) and c) uracil+ gallic acid (GU) at $298.15 \mathrm{~K}$ in $\mathrm{D}_{2} \mathrm{O}$

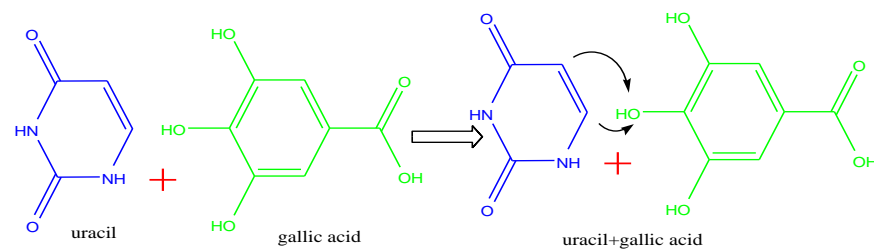

Scheme 1 Plausible solute-cosolute interaction C5 and C6 proton of uracil with phenolic $\mathrm{OH}$ group of gallic acid

\section{Conclusion}

It is evident from this study that there is a strong interaction between uracil and gallic acid and it becomes stronger with rise in temperature. As molecules of uracil and gallic acid are engaged each other, solute-cosolute interaction is much greater than the solute-solute and solvent-solvent interactions.

\section{Acknowledgement}

The authors are thankful to the Departmental Special Assistance Scheme under the University Grants Commission, New Delhi (no. 540/6/DRS/2007, SAP-1), India for financial support and instrumental facilities in order to continue this research work.

One of the authors, Prof. M.N. Roy, is thankful to University Grant Commission, New Delhi, Government of India for being awarded onetime grant under Basic Scientific Research via the grant-in-Aid no. F.4-10/2010 (BSR) regarding his active service for augmenting of research facilities to facilitate further research work.

\section{References}

[1] R.N. Saladi, A.N. Persaud, The causes of skin cancer: a comprehensive review, Drugs Today (Barc.) 41 (2005) 37-53.

[2] A. Gescher, U. Pastorino, S.M. Plummer, M.M. Manson, Suppression of tumour development by substances derived from the diet - mechanisms and clinical implications, Br. J. Clin. Pharmacol. 45 (1998) 1-12.

[3] M.M. Manson, Cancer prevention - the potential for diet to modulate molecular signalling, Trends Mol. Med. 9 (2003) 11-18.

[4] T.C. Reddy, P. Aparoy, N.K. Babu, K.A. Kumar, S.K. Kalangi, P. Reddanna, Kinetics and docking studies of a COX-2 inhibitorisolated from Terminalia bellerica fruits, Protein Pept. Lett. 17 (2010) 1251-1257.

[5] T. Chandramohan Reddy, D. Bharat Reddy, A. Aparna, K.M. Arunasree, G. Gupta et al., Anti-leukemic effects of gallic acid on human leukemia K562 cells: downregulation of COX-2, inhibition of BCR/ABL kinase and NF-kappaB inactivation, Toxicol. In Vitro 26 (2012) 396-405.

[6] D. Davidson, O. Baudisch, The preparation of uracil from urea, J. Am. Chem. Soc. 48 (1926) 2379-2383.

[7] P. Molnar, L. Marton, R. Izrael, H.L. Palinkas, B.G. Vertessy, Uracil moieties in Plasmodium falciparum genomic DNA, FEBS Open Bio 8 (2018) 1763-1772.

[8] K. Séron, Marie-Odile Blondel, R. Haguenauer-Tsapis, C. Volland, Uracilinduced Down-regulation of the yeast uracil permease, J. Bacteriol. 181 (1999) 1793-1800

[9] D.P. Shoemaker,C.W. Garland, Experiments in physical chemistry, McGraw-Hill Publishers, New York, 1967, pp.131-138.

[10] A. Bhattacharjee, M.N. Roy, Ion association and solvation behaviour of tetraalkyl ammonium iodides in binary mixture of dichloromethane $+\mathrm{N}, \mathrm{N}$ dimethyl formamide probed by conductometric study, Phys. Chem. Chem. Phys. 12 (2010) 1-9.

[11] D. Ekka, M.N. Roy, Quantitative and qualitative analysis of ionic salvation of individual ions of imidazolium based ionic liquids in significant solution systems by conductance and FT-IR spectroscopy, RSC Adv. 4 (2014) 1983119845.

[12] M.N. Roy, S. Saha, S. Barman, D. Ekka, Host-guest inclusion complexes of RNA nucleosides inside aqueous cyclodextrins explored by physicochemical and spectroscopic methods, RSC Adv. 6 (2016) 8881-8891.

[13] D.O. Masson, Ion-solvent interactions, Phil. Mag. 8 (1929) 218-235

[14] F.J. Millero, The partial molal volumes of electrolytes in aqueous solution. In: R.A. Horne (Ed.), Water and aqueous solutions: Structure, thermodynamics and transport process, Wiley Interscience, New York, 1972, pp.519-595.

[15] L.G. Hepler, Studies on viscosities and densities of $\mathrm{R}_{4} \mathrm{NX}$ in ME + water mixtures of different temperatures, Can. J. Chem. 47 (1969) 4613-4617.

[16] M.N. Roy, V.K. Dakua, B. Sinha, Partial molar volumes, viscosity B-coefficients and adiabatic compressibilities of sodium molybdate in aqueous 1,3-dioxalane mixture from 303.15 to $323.15 \mathrm{~K}$ Int. J. Thermophys. 28 (2007) 1275-1284.

[17] G. Jones, D. Dole, The viscosity of aqueous solutions of strong electrolytes with special reference to barium chloride, J. Am. Chem. Soc. 51 (1929) 2950-2964.

[18] J.D. Pandey, K. Mishra, A. Shukla, V. Mishran, R.D. Rai, Apparent molal volume, apparent molal compressibility, verification of jones-dole equation and thermodynamic studies of aqueous urea and its derivative, Thermochim. Acta 117 (1987) 245-259.

[19] F.J. Millero, The molal volumes of electrolytes, Chem. Rev. 71 (1971) 147-176

[20] V. Minkin, O. Osipov, Y.Zhdanov, Dipole moments in organic chemistry, Plenum Press, New York, 1970

[21] M. Born, E. Wolf, Principles of optics: Electromagnetic theory of propagation, interference and diffraction of light, $7^{\text {th }}$ Edn., Cambridge University Press, London, 1999.

[22] M. Deetlefs, K. Seddon, M. Shara, Predicting physical properties of ionic liquid, Phys. Chem. Chem. Phys. 8 (2006) 642-649.

[23] S. Kamathama, N. Kumar, Padmaja Gudipalli, Isolation and characterization of gallic acid and methyl gallate from the seed coats of Givotia rottleriformis Griff. and their anti-proliferative effect on human epidermoid carcinoma A431 cells, Toxicol. Rep. 2 (2015) 520-529. 